\title{
Clomifeencitraat voor hypogonadale klachten: bijna 10 jaar ervaring
}

\author{
Manou Huijben · M. W. T. Tycho Lock
}

Geaccepteerd op: 13 januari 2022 / Published online: 14 februari 2022

(C) The Author(s) 2022

Samenvatting Hypogonadisme is een wereldwijd probleem onder mannen dat seksuele, fysieke en mentale problemen veroorzaakt. Clomifeencitraat (CC) is een alternatieve, offlabel therapie, vooral voor mannen met een actieve of toekomstige kinderwens. In deze single-centerstudie werden 153 mannen die behandeld werden met CC voor hypogonadisme retrospectief geëvalueerd. Uitkomstmaten waren onder andere hormonale evaluatie, hypogonadale symptomen, metabole en lipidenparameters, veiligheidsaspecten en bijwerkingen. Tijdens de behandeling nam het totaal testosteron toe van 9 naar $16 \mathrm{nmol} / \mathrm{l}$, met een biochemische toename in $89 \%$ van de patiënten. Verhoogd niveau van totaal testosteron hield aan na acht jaar behandeling. Bij behandeling met CC ervoer $74 \%$ van de patiënten verbetering van de hypogonadale symptomen. Laag-normaal luteïniserend hormoon vóór CC-behandeling was voorspellend voor een betere testosteronrespons. Tijdens CC-therapie werden weinig, niet-ernstige bijwerkingen gemeld. Concluderend, CC is een effectieve therapie op korte en lange termijn, die zowel klinische symptomen als biochemische markers van mannelijk hypogonadisme verbetert met weinig bijwerkingen en goede veiligheidsaspecten.

Trefwoorden clomifeencitraat · mannelijk hypogonadisme $\cdot$ testosterondeficiëntiesyndroom

De inhoud van dit artikel zal ook aangeboden worden aan een Engelstalig tijdschrift.

drs. M. Huijben $(\bowtie) \cdot$ drs. M. W. T. T. Lock

afdeling Urologie, Universitair Medisch Centrum Utrecht, Utrecht, Nederland

m.huijben@umcutrecht.nl

\section{Clomiphene citrate in hypogonadism: almost 10 years of experience}

Abstract Hypogonadism, is a worldwide problem among men that causes sexual, physical and mental problems. Clomiphene citrate (CC) is an alternative, off-label therapy, especially for men with an active or future child wish. In this single-center study, 153 men treated with CC for hypogonadism were retrospectively analyzed. Outcome measures included hormonal evaluation, hypogonadal symptoms, metabolic and lipid parameters, safety aspects and side-effects. During treatment, total testosterone increased from 9 to $16 \mathrm{nmol} / \mathrm{l}$, with a biochemical improvement in $89 \%$ of the patients. Increased levels of total testosterone held after eight years of treatment. With CC treatment, $74 \%$ of patients experienced improvement of hypogonadal symptoms. Low to normal luteinizing hormone before CC treatment was a predictor for better testosterone response. Few, nonserious side-effects were reported during CC therapy. In conclusion, CC is an effective short- and long-term treatment, improving both clinical symptoms and biochemical aspects of male hypogonadism, with few side-effects and good safety aspects.

Keywords clomiphene citrate $\cdot$ male hypogonadism . testosterone deficiency syndrome

\section{Proloog}

Al meer dan 30 jaar volgt de tweede auteur van dit artikel de annual meetings van de American Association of Urology (AUA) en de American Society of Andrology (ASA) op de voet. Op die meetings werd aanvankelijk weinig belangstelling geschonken aan de behandeling van hypogonadale klachten bij mannen, zo stelde hij vast. Dit beeld veranderde echter dra- 
matisch toen rond de eeuwwisseling de transdermale testosterongel werd geïntroduceerd. De testosteronmarkt 'explodeerde' en op dubieuze indicaties werden (én worden) 'ad libitum' testosteronpreparaten voorgeschreven, vooral in de eerste lijn in Amerika, helaas ook aan mannen met een kinderwens. Dat er sinds die eerste 'wilde jaren' ook meer aandacht is gekomen voor hypogonadisme blijkt uit de strakkere richtlijnen voor gebruik van clomifeencitraat (CC) en de toename van het aantal voordrachten en posters over het offlabel gebruik van CC op de AUA- en ASAmeetings. Rond 2010 heeft diezelfde auteur dan ook besloten om consequent bij alle hypogonadale mannen medicamenteuze behandeling te starten met het extreem goedkope CC.

Gezien de schaarse literatuur over de werkzaamheid van CC bij hypogonadale mannen is samen met de eerste auteur een nauwkeurige analyse van deze patiëntengroep verricht waarvan in dit artikel de resultaten worden gepresenteerd.

\section{Introductie}

Hypogonadisme bij mannen is een biochemisch én klinisch testosterondeficiëntiesyndroom met een prevalentie van symptomatisch hypogonadisme van $2,1-5,7 \%$ bij mannen boven de 30 jaar [1-4]. De prevalentie neemt toe met de leeftijd en in combinatie met de aanwezigheid van hart- en vaatziekten, diabetes mellitus (DM), obesitas en maligniteit [2, 5]. Verminderd libido, gebrek aan energie, stemmingswisselingen, verminderde spiermassa en erectiestoornissen zijn veel voorkomende hypogonadale symptomen [6, 7]. Testosterontherapie (TTh) is de behandeling van eerste keuze voor mannelijk hypogonadisme [8]. Exogeen testosteron leidt echter tot negatieve feedback op de hypothalamus-hypofysegonadale (HPG) as, waardoor de endogene testosteronproductie en spermatogenese worden onderdrukt [9]. Andere bijwerkingen zijn veranderde serumlipiden, polycythaemia en, zelden, gynaecomastie [9-11].

Met CC is een alternatieve offlabel farmacologische behandeling beschikbaar gekomen voor mannelijk hypogonadisme. CC is een selectieve oestrogeenreceptormodulator, die oestrogeenreceptoren in de hypothalamus en hypofyse blokkeert, wat leidt tot verhoogde secretie van luteïniserend hormoon (LH) en follikelstimulerend hormoon (FSH), waardoor de endogene testosteronproductie van de testikels wordt gestimuleerd en de spermatogenese in stand wordt gehouden (fig. 1; [12]).

Sinds de jaren zestig van de vorige eeuw wordt CC vaak gebruikt voor ovulatie-inductie bij vrouwen in doseringen van $50-150 \mathrm{mg} / \mathrm{dd}$. Voor mannen keurde de Amerikaanse Food and Drug Administration (FDA) het geneesmiddel niet goed vanwege het onduidelijke klinische effect ervan, omdat goed gecontroleerde en goed onderbouwde studies ontbraken [13-15]. CC wordt echter al meer dan 30 jaar beschreven als of-

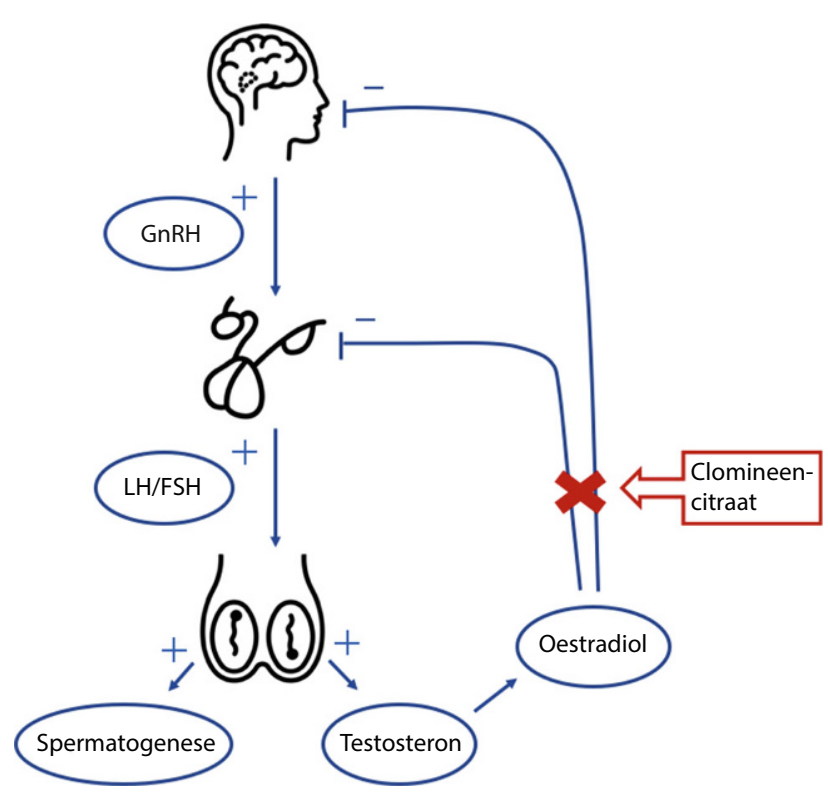

Figuur 1 Effect van clomifeencitraat op de hypothalamushypofyse-gonadale as

flabel therapie voor hypogonadale mannen, vooral zij met een actieve of toekomstige kinderwens, of hypogonadale mannen die geen TTh willen gebruiken [16]. In vergelijking met TTh is CC gemakkelijk in gebruik, met minimale kosten.

In ons land zijn de kosten van CC bijvoorbeeld tot 40 keer lager dan die van reguliere TTh, afhankelijk van de gebruikte dosis [17].

Uit een recente meta-analyse bleek dat CC bij hypogonadale mannen het testosteronniveau naar normaalwaardes verbeterde en daarnaast ook symptoomverbetering liet zien op een objectieve, hypogonadisme symptoomvragenlijst. Gezien het multivariabele karakter van het ontstaan van hypogonadale symptomen is de invloed van CC hierop nog onduidelijk dosis [18]. Het doel van de huidige studie was om de langetermijndata van het Universitair Medisch Centrum (UMC) Utrecht ten aanzien van de invloed van CC op zowel hypogonadale symptomen als testosteron te evalueren bij hypogonadale mannen.

\section{Methode}

\section{Studieopzet}

Er werd een retrospectieve, single-centerstudie uitgevoerd. Alle hypogonadale mannen die tussen januari 2012 en januari 2021 in het UMC Utrecht met CC waren behandeld, werden geïncludeerd. Ethische goedkeuring voor deze retrospectieve studie werd verkregen van de Medisch Ethische Toetsingscommissie (METC) Utrecht (WAG/mb/20/500309). Alle patiënten werden geïnformeerd dat CC wordt gebruikt als een offlabel therapie. 


\section{Patiëntenpopulatie}

Mannen ouder dan 18 jaar met lage of relatief laag totaal testosteron (TT) gehalte en hypogonadale symptomen, die daarvoor behandeling met CC ontvingen, werden geïncludeerd. Patiënten werden geëxcludeerd indien: er geen evaluatie was van serumtestosteron voor of tijdens de behandeling, CC werd gebruikt in combinatie met TTh, humaan choriongonadotrofine (hCG) of aromataseremmers (AI) of als TTh, hCG of AI werden gebruikt binnen één maand na CC-initiatie. Mannen kregen CC, met een startdosering van $25 \mathrm{mg}$ om de dag, of $25-50 \mathrm{mg}$ per dag bij een lichaamsgewicht boven de $100 \mathrm{~kg}$. De dosering werd verhoogd tot $50 \mathrm{mg}$ per dag wanneer er weinig biochemische respons was. Gegevens over duur van CC-therapie, patiëntkenmerken (leeftijd, body mass index [BMI], obesitas $\left[\right.$ BMI $\left.>25 \mathrm{~kg} / \mathrm{m}^{2}\right]$ ), testiculair volume, medische voorgeschiedenis (hiv, testiculaire chirurgie, DM, hart- en vaatziekten, diagnose Klinefelter-syndroom, maligniteiten, polycytemie) en aanvullende medicatie voor erectiestoornissen tijdens de behandeling werden handmatig verkregen uit patiëntendossiers.

\section{Uitkomsten}

Primaire uitkomsten van het onderzoek waren hormonale beoordeling bij baseline en na één, drie, zes en 12 maanden tijdens CC-therapie en daarna jaarlijks, gemeten met immunoassay (Atellica ${ }^{\circledR}$, Siemens, Erlangen, Duitsland).

De immunoassay werd tijdens follow-up vervangen, maar de hormonale waarden waren vergelijkbaar met beide immunoassay-tools:

1. totaal testosteron (TT) van bloedafname in de vroege ochtend (<10 uur) (norm: 7,0-31 nmol/l);

2. vrij testosteron (FT) van bloedafnames in de vroege ochtend (<10 uur) (norm: 230-600 pmol/l);

3. luteïniserend hormoon (LH) (norm: 1,0-9,0 IE/l);

4. follikelstimulerend hormoon (FSH) (norm: 1,019,0 IE/l);

5. oestradiol (norm: $70-200 \mathrm{pmol} / \mathrm{l}$ );

6. geslachtshormoonbindend globuline (SHBG) (norm: $10-40 \mathrm{nmol} / \mathrm{l}$ );

7. albumine (norm: $35,0-50,0 \mathrm{~g} / \mathrm{l}$ );

8. prolactine (norm: $0,10-0,65 \mathrm{IE} / \mathrm{l}$ ).

9. Secundaire uitkomsten waren: aanwezigheid van hypogonadale symptomen gemeten op baseline; subjectieve symptoomverbetering werd geëvalueerd tijdens follow-up (FU);

10. BMI, HbAlc, serum totaal cholesterol, triglyceriden, low density-lipoproteïne (LDL), high densitylipoproteïne (HDL) en niet-HDL-cholesterol, voor en tijdens de behandeling;

11. zelfgerapporteerde bijwerkingen werden opgemerkt tijdens de behandeling;

12. hematocriet $(\mathrm{Ht})$, hemoglobine $(\mathrm{Hb})$, trombocyten, alanineaminotransferase (ALAT), aspartaataminotransaminase (ASAT), alkalische fosfatasen
(AF), gamma-glutamyl-transpeptidase (gGT) en totaal prostaatspecifiek antigeen (PSA) voor en tijdens de behandeling;

13. gegevens over de aanwezigheid van een proefstop van CC-therapie, de reden en duur van een proefstop, veranderingen in TT, FT en symptomen tijdens de proefstop en of patiënten na de proefstop de CC-therapie hervatten.

\section{Gegevensanalyse}

Gegevens werden geregistreerd en in tabellen geordend met Microsoft Excel ${ }^{\circledR}$-software. Waarden werden gepresenteerd als aantal (\%), gemiddelde (standaarddeviatie $[\mathrm{SD}])$ of mediaan $\left(25^{\mathrm{e}}-75^{\mathrm{e}}\right.$ percentiel interkwartielafstand [IQR]) als de gegevens niet normaal verdeeld waren. Normaliteit van continue variabelen werd getest met de Shapiro-Wilk-test, histogrammen en normaliteitskwantielplots. De gepaarde steekproef $t$-test werd gebruikt om hormonale niveaus, veiligheidsaspecten, serumlipiden en BMI van voor en tijdens de behandeling met elkaar te vergelijken. De door Wilcoxon ondertekende gerangschikte test werd gebruikt als de gegevens niet voldeden aan de aannames voor normaliteit. Aannames voor correlatieanalyse waren normaliteit, homoscedasticiteit en lineariteit. Bivariate correlatie werd berekend met de Pearsons correlatiecoëfficiënt en als de gegevens niet voldeden aan de aanname voor normaliteit werd de Spearmans rangcorrelatiecoëfficiënt berekend. Een $p$-waarde $\leq 0,050$ werd als statistisch significant beschouwd. Statistische analyse werd uitgevoerd met behulp van SPSS (IBM SPSS Statistics, versie 25.0. Armonk, NY, VS: IBM Corp.).

\section{Resultaten}

\section{Studiepopulatie}

In totaal werden 173 mannelijke patiënten die waren behandeld met CC, gescreend voor inclusie. 20 patiënten werden uitgesloten; vier gebruikten CC gecombineerd met TTh of hCG, zes hadden geen uitwasperiode langer dan vier weken tussen TTh en het begin van de CC-therapie, bij twee had geen TT- en/of FT-meting plaatsgevonden vóór de behandeling en acht patiënten waren lost to follow-up vóór enige hormonale evaluatie. Uiteindelijk werden 153 patiënten geïncludeerd voor analyse. Gegevens over patiëntkenmerken, comorbiditeit en dosering bij aanvang van de behandeling zijn weergegeven in tab. 1. Bij 41 patiënten werd een orchidectomie uitgevoerd, 22 van deze patiënten $(54 \%)$ werden aanvullend behandeld met chemotherapie, radiotherapie of een combinatie daarvan. De mediane duur van de CC-therapie was 10 maanden (range 1-96). Tijdens het eerste jaar van CC waren 21 patiënten lost to follow up (14\%) en stopten $50(33 \%)$ patiënten met de behandeling. Op het 
Tabel 1 Patiëntkarakteristieken op baseline

\begin{tabular}{|c|c|c|}
\hline karakteristieken & totaal 153 patiënten & \\
\hline leeftijd, mean $\pm S D$ (range), jaren & $48,6 \pm 12,8(22-80)$ & $(n=153)$ \\
\hline overwicht (BMI > 25kg/m²), $n(\%)$ & $75(67)$ & $(n=112)$ \\
\hline testisvolume & & $(n=75)$ \\
\hline - linker testis, mediaan (IQR) & $18,0(15,0-20,0)$ & \\
\hline - rechter testis, mediaan (IQR) & $18,0(15,0-18,0)$ & \\
\hline medische voorgeschiedenis & & $(n=153)$ \\
\hline - Klinefelter, $n(\%)$ & $1(1)$ & \\
\hline - orchidectomie, $n(\%)$ & $41(27)$ & \\
\hline - orchidopexie, $n(\%)$ & $5(3)$ & \\
\hline - vasectomie, $n(\%)$ & $17(11)$ & \\
\hline - vasovasostomie, $n(\%)$ & $3(2)$ & \\
\hline - diabetes mellitus (DM), $n$ (\%) & $15(10)$ & \\
\hline - testiculaire tumoren, $n(\%)$ & $38(23)$ & \\
\hline - andere maligniteiten ${ }^{\mathrm{a}}, n(\%)$ & $16(10)$ & \\
\hline - hypofyseadenoom, $n(\%)$ & $2(1)$ & \\
\hline - hiv, $n(\%)$ & $3(2)$ & \\
\hline - myocard- of herseninfarct, $n(\%)$ & $16(10)$ & \\
\hline - hypertensie, $n(\%)$ & $19(12)$ & \\
\hline - trombose of -embolie, $n(\%)$ & $5(3)$ & \\
\hline - polycytemie, $n(\%)$ & $2(1)$ & \\
\hline dosis van CC-therapie bij aanvang ve & an de behandeling & $(n=153)$ \\
\hline$-25 \mathrm{mg} / 2$ dagen & $132(86)$ & \\
\hline$-25 \mathrm{mg} / \mathrm{dag}$ & $9(6)$ & \\
\hline - $50 \mathrm{mg} / 2$ dagen & $6(4)$ & \\
\hline - $50 \mathrm{mg} / \mathrm{dag}$ & 3 (2) & \\
\hline - $25 \mathrm{mg} / 3$ dagen & $1(1)$ & \\
\hline - alternerend 25 of $50 \mathrm{mg} / \mathrm{dag}$ & $1(1)$ & \\
\hline $\begin{array}{l}n \text { aantal patiënten, } B M I \text { body mass in } \\
\text { kwartielafstand } \\
\text { a Betreft prostaatcarcinoom, niercelc } \\
\text { coloncarcinoom, rectumcarcinoom. }\end{array}$ & $\begin{array}{l}\text { ndex, SD standaarddevi } \\
\text { sarcinoom, lymfoom, Ka }\end{array}$ & $\begin{array}{l}\text { QR inter- } \\
\text { sarcoom, }\end{array}$ \\
\hline
\end{tabular}

eindpunt van deze studie (januari 2021) waren 43 patiënten (28\%) nog steeds in de follow-up, 26 patiënten (17\%) waren lost to follow-up, 71 patiënten (46\%) stopten met CC-therapie en 14 patiënten (9\%) stopten met CC en schakelden over naar TTh. De dosering werd verhoogd ( $n=22,14 \%$ ) bijminimale TT-respons of verlaagd als binnen het eerste jaar bijwerkingen optraden $(n=10,7 \%)$.

\section{Hormonale evaluatie}

Gegevens over hormonale spiegels worden gegeven in tab. 2, alle patiënten hadden vóór de behandeling TT-spiegels < $15 \mathrm{nmol} / \mathrm{l}$. Bij de eerste meting tijdens de behandeling nam de mediane TT-spiegel toe van 9 naar $16 \mathrm{nmol} / \mathrm{l}$, met een biochemische toename bij 136 patiënten (89\%) tijdens CC-therapie (tab. 3). Bij 15 patiënten $(10 \%)$ nam de TT-spiegel niet toe; deze patiënten stopten met de behandeling tussen één en drie maanden na aanvang van de therapie, zonder correlatie met de TT-, LH- en FSH-spiegels vóór de behandeling, de leeftijd en de oorsprong van het hypogonadisme. Twee patiënten (1\%) hadden een om- gekeerde TT-respons, gedefinieerd als een significante afname van de TT- en LH-spiegels. De eerste meting tijdens de behandeling vond plaats na gemiddeld 1,5 maanden (range 1-12). De TT-, FT-, LH-, FSH- en SHBG-spiegels namen toe en die van albumine nam af bij de eerste meting tijdens de behandeling, en daarna jaarlijks tot acht jaar follow-up ( $p=0,050$ ) (fig. 2 en 3).

\section{Hypogonadale symptomen}

Tabel 4 beschrijft hypogonadale symptomen voor en tijdens de behandeling. Symptomen op baseline werden gemeld bij 151 patiënten; bij twee patiënten was er, afgezien van een laag testosterongehalte, geen duidelijkheid over de aanwezigheid van symptomen vóór de behandeling. Tijdens de behandeling rapporteerde $74 \%$ van de patiënten een subjectieve verbetering van de symptomen, met een mediane duur totdat verbetering optrad van drie maanden (range 1-24). Verbetering van de andere symptomen (depressieve gedachten, verminderde energie, zwakke spierkracht, stemmingsverandering, gynaecomastie en agitatie) werden niet consistent gerapporteerd in patiëntendossiers. Symptoomverbetering werd opgemerkt bij $81 \%$ van de patiënten bij wie een biochemische stijging van het testosteronniveau optrad en bij $27 \%$ van de patiënten zonder een dergelijke stijging (tab. 2).

\section{Metabole en lipidenparameters}

In tab. 4 is ook het metabole en lipidenprofiel opgenomen. Het totaal cholesterol, LDL-, HDL- en niet-HDLcholesterol daalden tijdens de behandeling $(p<0,050)$. Het is onduidelijk of deze waarden zijn gebaseerd op nuchtere bloedtests.

\section{Veiligheidsaspecten en bijwerkingen}

In tab. 5 is een overzicht van de veiligheidsaspecten opgenommen. Twee patiënten ontwikkelden een marginaal verhoogd Ht tijdens CC-therapie (0,511/1); informatie over het $\mathrm{Ht}$ op baseline was echter niet beschikbaar. Bij één patiënt werd de CC-therapie stopgezet na verhoging van het $\mathrm{Ht}(0,51)$. Bij de andere patiënt met een Ht van 0,50 werd de CC-therapie voortgezet onder monitoring van het Ht. Eén patiënt, met een voorgeschiedenis van trombose in de onderste extremiteit, ontwikkelde een longembolie in het vierde jaar van de follow-up; 16 patiënten $(10 \%)$ hadden bijwerkingen: opvliegers $(n=5)$, agitatie $(n=4)$, visuele veranderingen $(n=2)$, gevoelige tepels $(n=2)$, stemmingsverandering $(n=1)$, gewichtstoename $(n=1)$, duizeligheid $(n=1)$ en hoofdpijn $(n=1)$.

\section{Proefstop}

52 patiënten kregen een proefstop van CC-therapie (34\%), met een mediane duur van drie maanden (range 1-12). 


\title{
Hier staat een advertentie.
}

\author{
$c$ bohn

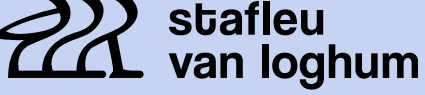 \\ Springer Media
}

Houten 2021 


\title{
Hier staat een advertentie.
}

\author{
$c$ bohn

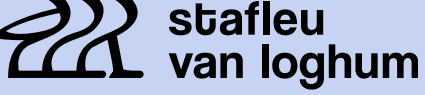 \\ Springer Media
}

Houten 2021 


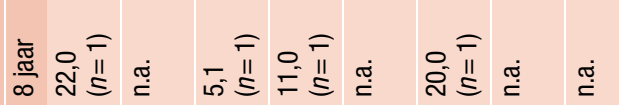

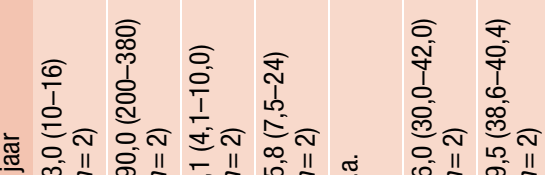

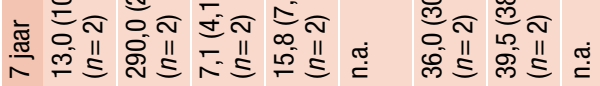

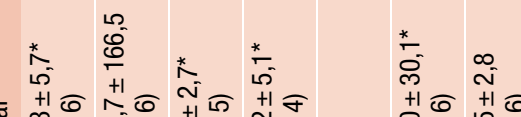

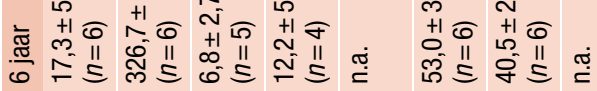

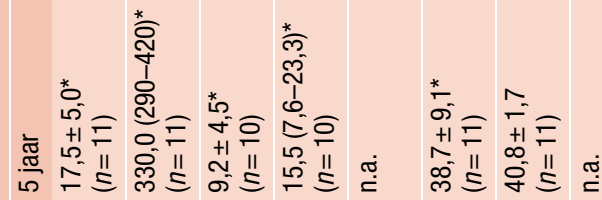

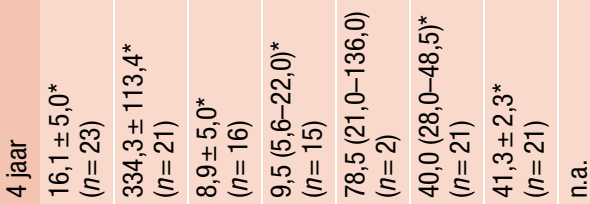

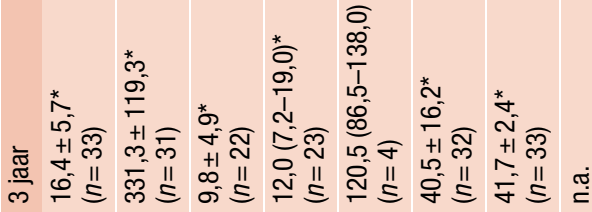

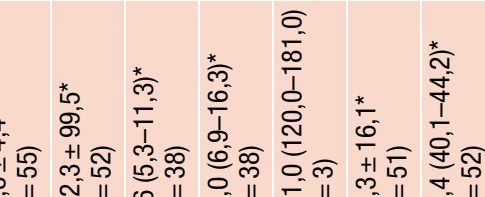

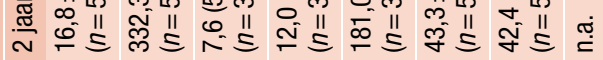




\section{Artikel}

Tabel 3 Biochemische en klinische respons op CC-therapie

totale populatie biochemische respons ( $n=153$ )

totale populatie klinische respons $(n=151)$

symptomatische verbetering $(74 \%) \quad$ geen symptomatische verbetering $(26 \%)$

biochemische stijging ( $n=136,89 \%)$

$81 \%$

$19 \%$

geen biochemische stijging $(n=15,10 \%)$

$27 \%$

$73 \%$

omgekeerde TT-reactie $(n=2,1 \%)$

$0 \%$

$100 \%$

$n$ aantal patiënten, $T T$ totaal testosteron

Tabel 4 Klinische aspecten van hypogonadisme en metabolische en lipide parameters voor en tijdens clomifeencitraat (CC) therapie. Data weergegeven in aantal patiënten (\%), gemiddelde \pm SD of mediaan (IQR)

\begin{tabular}{|c|c|c|}
\hline & voor CC-therapie & tijdens CC-therapie \\
\hline zelfgerapporteerde symptomen: & aanwezigheid van symptomen $(n=151)$ & verbetering van symptomen \\
\hline - verminderd libido & $86(57)$ & $43(50)$ \\
\hline - erectiele disfunctie & $84(56)$ & $44(52)$ \\
\hline - moeheid & $79(52)$ & $57(72)$ \\
\hline - depressieve gedachten & $11(7)$ & n.a. \\
\hline - verminderde energie & $10(6)$ & n.a. \\
\hline - verminderde spierzwakte & $6(4)$ & n.a. \\
\hline - gynaecomastie & $5(3)$ & n.a. \\
\hline - gedragsverandering & $4(3)$ & n.a. \\
\hline - agitatie & $3(2)$ & n.a. \\
\hline BMI, $\mathrm{kg} / \mathrm{m}^{2}$ & $27,9 \pm 4,4(n=100)$ & $28,1 \pm 3,5(n=12)$ \\
\hline $\mathrm{HbA} 1 \mathrm{c}, \mathrm{mmol} / \mathrm{mol}$ & $36,5(33,2-45,3)(n=16)$ & $36,0(35,0-39,3)(n=26)$ \\
\hline totaal cholesterol, $\mathrm{mmol} / \mathrm{l}$ & $5,5 \pm 1,1(n=43)$ & $4,8 \pm 1,2(n=41)^{\star}$ \\
\hline LDL-cholesterol, mmol// & $3,3 \pm 1,1(n=42)$ & $2,7 \pm 1,1(n=39)^{\star}$ \\
\hline HDL-cholesterol, mmol/l & $1,1(0,4)(n=44)$ & $1,06(0,9-1,3)(n=42)^{*}$ \\
\hline triglyceriden, $\mathrm{mmol} / \mathrm{l}$ & $1,8(1,3-3,2)(n=44)$ & $1,9(1,2-2,5)(n=41)$ \\
\hline non-HDL-cholesterol, mmol// & $4,3 \pm 1,1(n=41)$ & $3,7 \pm 1,6(n=42)^{\star}$ \\
\hline
\end{tabular}

Tabel 5 Serumparameters voor en tijdens de clomifeencitraat (CC) therapie. Data zijn weergegeven als gemiddelde \pm SD of mediaan (IQR)

\begin{tabular}{|c|c|c|c|c|c|c|c|c|c|c|}
\hline \multicolumn{11}{|c|}{ duur van de CC-therapie } \\
\hline & $\begin{array}{l}\text { voor CC- } \\
\text { therapie }\end{array}$ & eerste meting ${ }^{a}$ & 1 jaar & 2 jaar & 3 jaar & 4 jaar & 5 jaar & 6 jaar & 7 jaar & 8 jaar \\
\hline $\begin{array}{l}\text { hematocriet, } \\
\text { L/I }\end{array}$ & $\begin{array}{l}0,44 \pm 0,04 \\
(n=67)\end{array}$ & $\begin{array}{l}0,44 \pm 0,05 \\
(n=82)\end{array}$ & $\begin{array}{l}0,45 \pm 0,04^{*} \\
(n=41)\end{array}$ & $\begin{array}{l}0,45 \pm 0,04^{*} \\
(n=29)\end{array}$ & $\begin{array}{l}0,45 \pm 0,04 \\
(n=14)\end{array}$ & $\begin{array}{l}0,47 \pm 0,02^{*} \\
(n=12)\end{array}$ & $\begin{array}{l}0,47 \pm 0,02 \\
(n=4)\end{array}$ & $\begin{array}{l}0,44 \\
(0,44-0,46) \\
(n=3)\end{array}$ & $\begin{array}{c}0,50 \\
(n=1)\end{array}$ & $\begin{array}{c}0,50 \\
(n=1)\end{array}$ \\
\hline $\begin{array}{l}\text { hemoglobine } \\
\mathrm{mmol} / \mathrm{l}\end{array}$ & $\begin{array}{l}9,3(8,8-9,7) \\
(n=75)\end{array}$ & $\begin{array}{l}9,5(8,8-9,9) \\
(n=88)\end{array}$ & $\begin{array}{l}9,3 \pm 0,9 \\
(n=43)\end{array}$ & $\begin{array}{l}9,5 \pm 0,8 \\
(n=32)\end{array}$ & $\begin{array}{l}9,5 \pm 0,8 \\
(n=17)\end{array}$ & $\begin{array}{l}9,6 \pm 0,5 \\
(n=15)\end{array}$ & $\begin{array}{l}9,6 \pm 0,1 \\
(n=4)\end{array}$ & $\begin{array}{l}9,2 \pm 0,4 \\
(n=3)\end{array}$ & $\begin{array}{l}10,5 \\
(n=1)\end{array}$ & $\begin{array}{l}10,7 \\
(n=1)\end{array}$ \\
\hline $\begin{array}{l}\text { trombocyten, } \\
\times 10^{9} / /\end{array}$ & $\begin{array}{l}239 \pm 60 \\
(n=66)\end{array}$ & $\begin{array}{l}229 \pm 64 \\
(n=79)\end{array}$ & $\begin{array}{l}229 \pm 63 \\
(n=40)\end{array}$ & $\begin{array}{l}225 \pm 57 \\
(n=24)\end{array}$ & $\begin{array}{l}207 \pm 68^{*} \\
(n=14)\end{array}$ & $\begin{array}{l}210 \pm 70 \\
(n=12)\end{array}$ & $\begin{array}{l}160 \pm 39 \\
(n=3)\end{array}$ & $\begin{array}{l}198 \pm 61 \\
(n=3)\end{array}$ & $\begin{array}{l}222 \\
(n=1)\end{array}$ & $\begin{array}{l}200 \\
(n=1)\end{array}$ \\
\hline ALAT, U/I & $\begin{array}{l}28(19-38) \\
(n=56)\end{array}$ & $\begin{array}{l}26(19-34) \\
(n=63)\end{array}$ & $\begin{array}{l}24(19-35) \\
(n=32)\end{array}$ & $\begin{array}{l}31 \pm 11 \\
(n=16)\end{array}$ & $\begin{array}{l}23(22-51) \\
(n=12)\end{array}$ & $\begin{array}{l}32 \pm 16 \\
(n=9)\end{array}$ & $\begin{array}{l}28(23-33) \\
(n=2)\end{array}$ & $\begin{array}{l}26(22-29) \\
(n=2)\end{array}$ & n.a. & n.a. \\
\hline ASAT, U/I & $\begin{array}{l}26(23-31) \\
(n=51)\end{array}$ & $\begin{array}{l}28(22-32) \\
(n=62)\end{array}$ & $\begin{array}{l}28 \pm 10 \\
(n=29)\end{array}$ & $\begin{array}{l}27 \pm 5 \\
(n=14)\end{array}$ & $\begin{array}{l}27 \pm 8 \\
(n=11)\end{array}$ & $\begin{array}{l}23 \pm 9 \\
(n=8)\end{array}$ & $\begin{array}{l}29(22-35) \\
(n=2)\end{array}$ & $\begin{array}{l}33(24-42) \\
(n=2)\end{array}$ & n.a. & n.a. \\
\hline $\mathrm{AF}, \mathrm{U} / \mathrm{I}$ & $\begin{array}{l}80(68-94) \\
(n=52)\end{array}$ & $\begin{array}{l}73(59-82)^{*} \\
(n=58)\end{array}$ & $\begin{array}{l}70(55-84) \\
(n=27)\end{array}$ & $\begin{array}{l}67(60-104) \\
(n=13)\end{array}$ & $\begin{array}{l}68(55-76) \\
(n=12)\end{array}$ & $\begin{array}{l}67(61-77) \\
(n=9)\end{array}$ & $\begin{array}{l}88(79-97) \\
(n=2)\end{array}$ & $\begin{array}{l}115(114-115) \\
(n=2)\end{array}$ & n.a. & n.a. \\
\hline gGT, U/l & $\begin{array}{l}36(25-60) \\
(n=54)\end{array}$ & $\begin{array}{l}37(25-59) \\
(n=62)\end{array}$ & $\begin{array}{l}36(29-65) \\
(n=31)\end{array}$ & $\begin{array}{l}50(29-115) \\
(n=15)\end{array}$ & $\begin{array}{l}41(30-84) \\
(n=12)\end{array}$ & $\begin{array}{l}62 \pm 44 \\
(n=9)\end{array}$ & $\begin{array}{l}37(34-40) \\
(n=2)\end{array}$ & $\begin{array}{l}72(59-85) \\
(n=2)\end{array}$ & $\begin{array}{l}22 \\
(n=1)\end{array}$ & n.a. \\
\hline PSA, $\mu \mathrm{g} / \mathrm{I}$ & $\begin{array}{l}0,7(0,5-1,3) \\
(n=69)\end{array}$ & $\begin{array}{l}0,8(0,5-1,3) \\
(n=74)\end{array}$ & $\begin{array}{l}0,9(0,6-2,3) \\
(n=28)\end{array}$ & $\begin{array}{l}0,9(0,6-2,1) \\
(n=22)\end{array}$ & $\begin{array}{l}0,8(0,5-1,6) \\
(n=16)\end{array}$ & $\begin{array}{l}0,8(0,4-2,2) \\
(n=6)\end{array}$ & $\begin{array}{l}0,9(0,6-2,5) \\
(n=3)\end{array}$ & $\begin{array}{l}1,1 \pm 0,6 \\
(n=4)\end{array}$ & $\begin{array}{l}0,5 \\
(n=1)\end{array}$ & n.a. \\
\hline
\end{tabular}




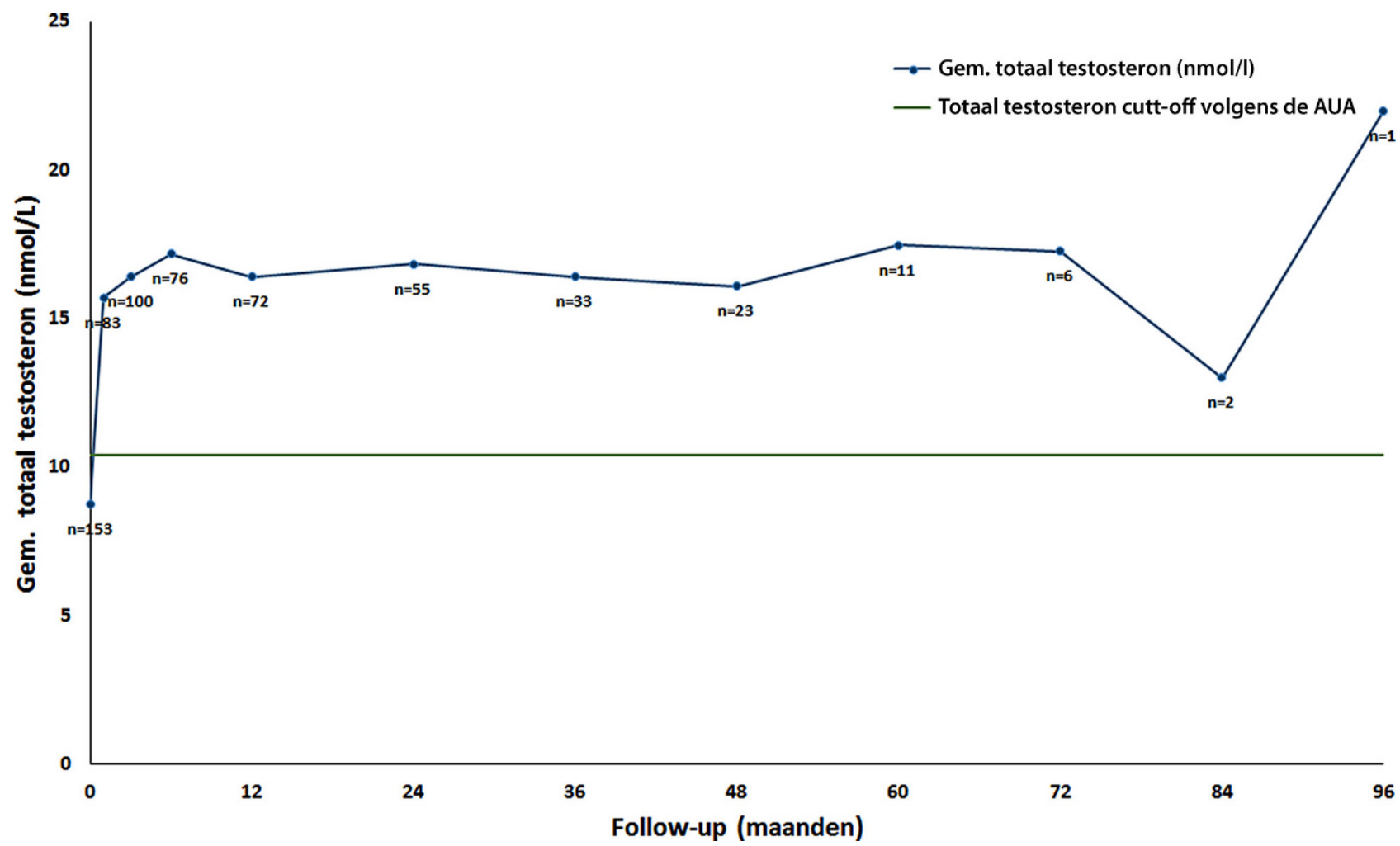

Figuur 2 Langetermijneffect van clomifeencitraat op het totaal cholesterol

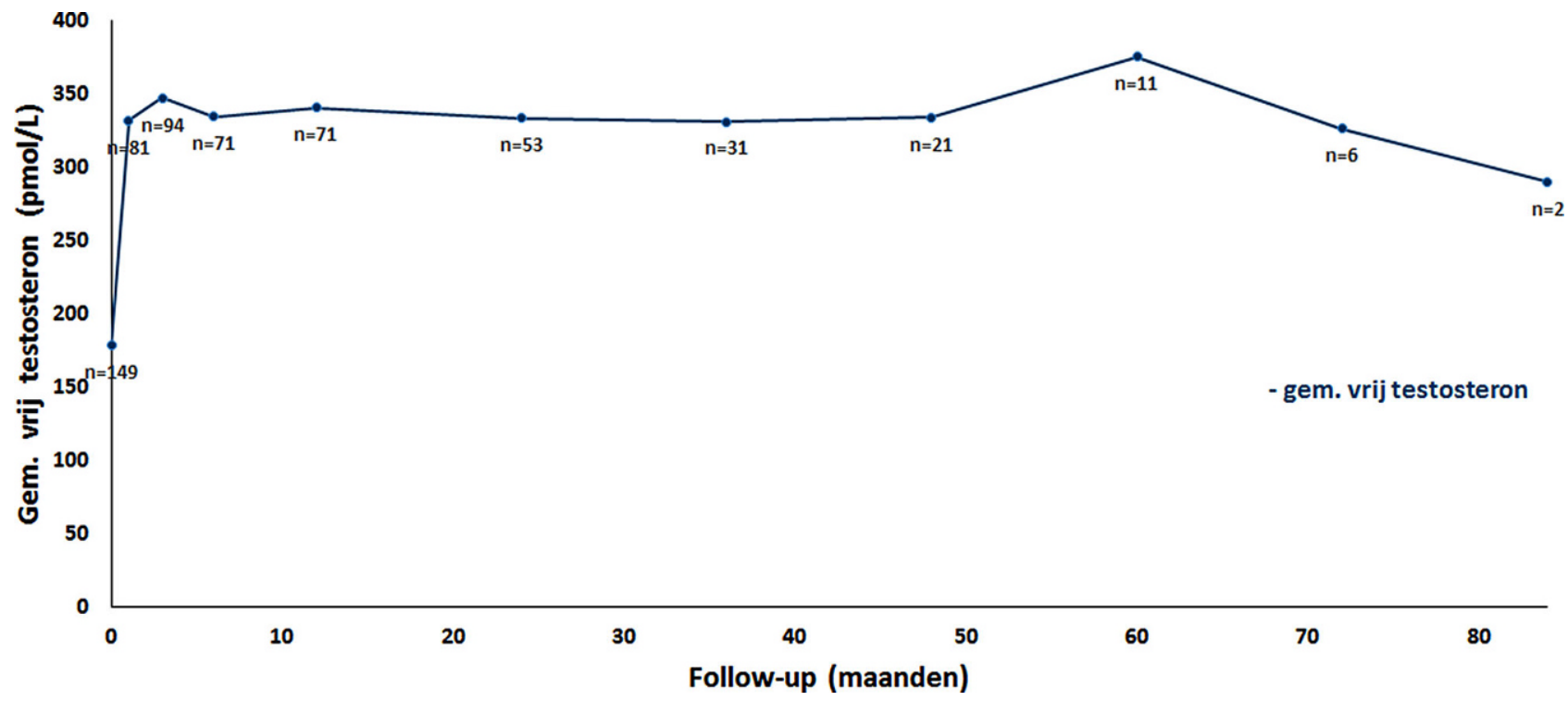

Figuur 3 Langetermijneffect van clomifeencitraat op vrij testosteron

Redenen voor die proefstop waren: door arts geïnitieerd testen van het effect van CC $(n=44 ; 85 \%)$, bijwerkingen (opvliegers, opwinding, stemmingsstoornis) $(n=4 ; 8 \%)$, opraken van medicatie $(n=3$; $6 \%)$ of extreem verhoogd oestradiol $(n=1 ; 2 \%)$. Tijdens de proefstop daalde de TT-spiegel significant bij $94 \%$ van de patiënten, met een gemiddeld TT tijdens de behandeling van 19,1 $(\mathrm{SD}=5,6) \mathrm{nmol} / \mathrm{l}$ en tijdens de proefstop van 10,8 $(\mathrm{SD}=3,1) \mathrm{nmol} / \mathrm{l}$ $(p=0,000)$. De gemiddelde FT tijdens CC-therapie was $373,2(\mathrm{SD}=126,6) \mathrm{pmol} / \mathrm{l}$ en tijdens proefstop 203,3 (SD=63,5) pmol/1 $(p=0,000)$. Klinisch zagen 20/52 patiënten een verslechtering van de symptomen tijdens de proefstop (38\%), namelijk: vermoeidheid $(n=12)$, libido $(n=8)$, depressieve gedachten $(n=3)$, erectiestoornissen $(n=2)$, agitatie $(n=2)$. 18/52 (35\%) patiënten hervatten de CC-therapie na de proefstop, van wie drie de patiënten met bijwerkingen. Bij $44 \%$ 
van de patiënten die geen verschil in symptomen opmerkten tijdens proefstop, waren de TT-spiegels tijdens de proefstop $>12 \mathrm{nmol} / \mathrm{l}$. Negen van de 35 patiënten (25\%) die niet opnieuw begonnen met CC na de proefstop hadden na behandeling een TT-spiegel van $>12 \mathrm{nmol} / 1$. Slechts $14(32 \%)$ van de patiënten bij wie de arts een proefstop initieerde, zetten de CCtherapie na de proefstop voort.

\section{Correlaties}

Er werd een correlatie gevonden tussen symptoomverbetering tijdens de behandeling en een grotere stijging van de TT-spiegel bij de eerste meting tijdens de behandeling ( $p=0,000 ; r=0,34)$. Een tweede correlatie werd gevonden tussen een lager bereik van normaal LH en FSH vóór de behandeling en een grotere stijging van de TT-spiegel bij de eerste meting tijdens de behandeling (resp. $p=0,000 ; r=-0,37$ en $p=0,000$; $r=-0,40)$. Een derde correlatie werd gevonden tussen een laag-normale LH-spiegel vóór de behandeling en verbetering van symptomen met CC-therapie $(p=0,020 ; r=-0,21)$. Verder werd een correlatie gevonden tussen een geringere stijging van de TT-spiegel bij de eerste meting en een orchidectomie in de medische geschiedenis $(p=0,009 ; r=-0,21)$. Er werden geen correlaties gevonden tussen de eerste meting tijdens CC-behandeling en leeftijd, BMI, testisvolume en aanwezigheid/geschiedenis van overgewicht, harten vaatziekten, chemo- en/of bestralingstherapie, DM en andere vormen van maligniteit.

\section{Omgekeerd effect van CC}

Twee patiënten hadden een omgekeerd biochemisch effect binnen de eerste drie maanden van de behandeling. Ze waren 30 en 40 jaar oud, beiden met een voorgeschiedenis van orchidectomie voor een puur seminoom. De patiënten gebruikten CC $25 \mathrm{mg}$ om de andere dag. TT-spiegels vóór de behandeling waren respectievelijk 3,7 en $6,1 \mathrm{nmol} / 1$ en tijdens CC-behandeling respectievelijk 0,5 en 1,3 nmol/1. De LH-spiegels vóór de behandeling waren respectievelijk 26 en 27 IE/l en tijdens de CC-behandeling respectievelijk 8,6 en 9,0 IE/l. Vóór de behandeling was bij beide patiënten sprake van vermoeidheid en een verminderd libido, één patiënt had erectiestoornissen. Tijdens de CC-behandeling trad geen verbetering of verslechtering van de symptomen op.

De behandeling werd stopgezet nadat een tweede bloedonderzoek dit omgekeerde effect bevestigde. Na het stoppen van de CC-therapie herstelde TT-spiegel zich het testosteronniveau bij beide patiënten tot het niveau van vóór de behandeling.

\section{Discussie}

Deze studie ondersteunt het bewijs voor de werkzaamheid op lange termijn van CC bij hypogonadale mannen met een toename van totaal testosteron, vrij testosteron en gonadotrofines en laat een totale biochemische toename van TT bij $89 \%$ van de patiënten zien. Daarbij werd bij $74 \%$ van de patiënten een klinisch effect van de CC-therapie waargenomen als verbetering van hypogonadale symptomen. In totaal had $81 \%$ van de patiënten zowel een biochemische als een klinische respons. Deze studie is, voor zover wij weten, de eerste grote retrospectieve cohortstudie naar zowel klinische als biochemische effecten van CC bij hypogonadale mannen met een lange followup en herkenning van potentiële voorspellers voor succes.

De TT-, FT-, LH-, FSH- en SHBG-spiegels stegen na aanvang van de behandeling. Verhoogde testosteronniveaus hielden tot acht jaar follow-up aan. Deze verbetering van de hormoonspiegels is beschreven in eerdere onderzoeken, waarbij een TT-niveau bij baseline werd aangetoond tussen de 7 en $11 \mathrm{nmol} / \mathrm{l}$ en bij de eerste meting tijdens CC-behandeling tussen de 16 en $24 \mathrm{nmol} / \mathrm{l}(n=34-400)$ [19-22]. In slechts $10 \%$ van de onderzoekspopulatie leidde CC-therapie níet tot een biochemische respons; al deze patiënten stopten met CC-therapie. De resultaten van testosteron en gonadotrofinen laten zien dat CC effectief is in het verhogen van de endogene testosteronsecretie door de HPG-as te stimuleren bij hypogonadale mannen. In onze studie werd slechts bij één patiënt een toename van het oestradiolniveau gezien, in tegenstelling tot bevindingen in eerdere studies [19, 20, 23, 24]. Een mogelijke verklaring zou kunnen zijn dat oestradiol werd gemeten in een klein aantal van onze onderzoekspopulatie ( $n=13)$. Bij twee jonge patiënten $(<1 \%)$ werd een omgekeerd effect van CC op de testosteronspiegel gevonden. Hoewel dit fenomeen al eerder in de literatuur is beschreven, is de fysiologie van dit paradoxale effect van CC onduidelijk [21, 25, 26].

Het is niet bekend of CC op de lange termijn effectief is. In onze studie was er een aanhoudend biochemisch effect van CC, waarbij de langste langetermijnfollow-up acht jaar bedroeg. Drie eerdere onderzoeken ( $n=29-120)$ gaven aan dat na 24 tot 52 maanden CC-gebruik de hormoonspiegels stabiel waren [19, 27, 28].

Het is de moeite waard om te focussen op de 52 patiënten die een CC-proefstop hadden om meer inzicht te krijgen in dit langetermijneffect. In de huidige studie was er een afname van TT-spiegels $<15 \mathrm{nmol} / 1$ na het stoppen van CC bij $94 \%$ van de patiënten en bij $65 \%$ van de patiënten daalde de TT-spiegels tot $<12,1 \mathrm{nmol} / \mathrm{l}$. Dit resultaat werd ondersteund door de studie van Marconi et al. (2016) $(n=27)$ waarin werd gerapporteerd dat bij $78 \%$ van de patiënten drie maanden na het stoppen met de CC-therapie een TTspiegel werd gevonden van $<10 \mathrm{nmol} / 1$ en dat die spiegel zes maanden na het stoppen bij alle patiënten werd gevonden [29]. 
Opmerkelijk is dat slechts $38 \%$ van de patiënten in de huidige studie een verslechtering van de hypogonadale symptomen meldde terwijl ze op proef stopten. Bovendien stopte in de huidige studie $33 \%$ van de patiënten met CC-behandeling in het eerste jaar, zonder correlatie tussen stopzetting in het eerste jaar en TT-niveaus vóór de behandeling, leeftijd of etiologie van het hypogonadisme. Een verklaring voor deze bevindingen zou kunnen zijn dat bij sommige mannen bij wie twijfel bestond over de relatie tussen symptomen en een (marginaal) laag testosterongehalte, CC werd gebruikt als een try-out om te zien of de symptomen verbeterden met een hogere testosteronspiegel. Een andere verklaring is het ontbreken van strikte inen exclusiecriteria vanwege het retrospectieve karakter van dit onderzoek. Hoewel de symptomatische effecten van CC moeilijk vast te stellen zijn, kunnen verbeterde testosteronniveaus die zijn verkregen door CC leiden tot andere (voor patiënten onzichtbare) voordelen, namelijk verbetering van de botdichtheid [27].

Bovendien is deze retrospectieve studie de eerste die aantoont dat een betere vroege respons van de TTspiegel gecorreleerd is met een betere klinische respons en dat een laag-normale LH-spiegel vóór de behandeling symptoomverbetering en een grotere toename van het TT tijdens CC-behandeling voorspelt. Deze potentiële voorspeller werd ook gezien in de studie van Mazzola et al. [23]. Zonder enig aangetoond mechanisme wordt verondersteld dat laag-normale LH-niveaus, potentieel beter zijn voor het stimuleren van Leydig-cellen door CC. Andere voorspellers werden reeds beschreven door Guay et al. ( $n=178)$, die aantoonden dat jongere leeftijd ( $<55$ jaar) en afwezigheid van DM een betere TT-respons voorspelt [30]. Dit werd niet gezien in onze studie. In een andere studie werden specifieke enzymen zoals het CYP450 D26-enzym gesuggereerd als voorspeller voor de TTrespons [24]. In onze studie en in eerdere studies werd dit CYP450 D26-enzym niet gemeten.

Bijwerkingen werden gemeld bij $10 \%$ van onze studiepopulatie en omvatten agitatie, opvliegers, gevoelige tepels, stemmingswisselingen, gewichtstoename, visuele veranderingen, hoofdpijn en duizeligheid. Deze bijwerkingen werden ook gerapporteerd in de literatuur, met een prevalentie van $4-11 \%[19,21$, 24,31 . De meeste patiënten in onze studie met bijwerkingen gingen door met CC na de proefstop, wat suggereert dat de voordelen van CC groter waren dan de bijwerkingen. Vanwege het off-label gebruik van CC bestaan er geen richtlijnen voor het monitoren van bijwerkingen, zoals verhoging van PSA, Hb en Ht. Daarom zijn aanbevelingen gebaseerd op ervaring met exogene TTh. Uit de literatuur blijkt dat TTh kan leiden tot een verhoging van PSA, Hb en Ht $[10,32]$. In ons onderzoek vonden we geen verhoging van PSA en $\mathrm{Hb}$ en vertoonden slechts twee patiënten een marginaal verhoogde Ht $(0,50$ en 0,51$)$ tijdens de behandeling. Baseline Ht-spiegels waren niet beschikbaar bij deze patiënten, dus het is ondui- delijk of dit verhoogde Ht pre-existent was. Dit werd ondersteund door de studie van Chandrapal et al. waarin geen toename te zien was van de PSA-, Hben Ht-spiegel tijdens CC-therapie $(n=77)$ [33]. Deze uitkomsten werden verder ondersteund door Krzastek et al. $(n=76)$, die slechts één patiënt vond met een verhoogde Ht-spiegel $(0,51)$ tijdens CC-therapie [19]. Wheeler et al. toonden een verschil aan in de prevalentie van een verhoogde Ht-spiegel met CC en TTh van respectievelijk 2 en $11 \%(n=363)$ [34]. Een hypothese is dat snelle piekstijgingen in TT-niveau en TT-overdosering, vooral bij TTh-injecties, kan leiden tot door de behandeling geïnduceerde verhoging van de Hb- en Ht-spiegel [35]. Dit geldt dus niet voor CCtherapie, met langzame verhoging van het endogene TT. Verder toonden Kavoussi et al. aan dat het risico op diepveneuze trombose niet verhoogd was met CC in vergelijking met de algemene bevolking $(n=1180)$ [36].

Er zijn verschillende tekortkomingen te benoemen van deze retrospectieve studie. Ten eerste is het een retrospectieve studie met gegevens die handmatig zijn verkregen uit het patiëntendossier. Er waren geen strikte inclusiecriteria met vooraf gedefinieerde baseline- en uitkomstmetingen. Er werd geen gevalideerd instrument voor het melden van hypogonadale symptomen gebruikt, maar zelfgerapporteerde hypogonadale symptomen en subjectieve symptoomverbetering werden geëvalueerd tijdens follow-up. Ten tweede werd bij 130 patiënten de aanwezigheid van bijwerkingen niet gemeld en werden bijwerkingen niet systematisch geclassificeerd. Dit heeft mogelijk geleid tot een onderschatting van de werkelijke prevalentie van bijwerkingen. Als laatste valt te vermelden dat de oorzaak van het hypogonadisme bij de geïncludeerde patiënten divers was. Door de bemoedigende resultaten van deze studie zijn wij echter van mening dat het zeer waardevol is om een prospectieve studie uit te voeren, vooral voor jonge hypogonadale mannen met een actieve of potentiële toekomstige kinderwens die niet in aanmerking komen voor TTh, met duidelijke inclusiecriteria, adequate meting van hormonale niveaus en symptomatologie (gevalideerde vragenlijsten!), en registratie van bijwerkingen.

\section{Conclusie}

Behandeling van hypogonadale mannen met clomifeencitraat heeft een veelbelovend effect op zowel klinische symptomen als biochemische testosteroninsufficiëntie van deze mannen met weinig gemelde bijwerkingen en goede veiligheidsaspecten in vergelijking met testosterontherapie. Daarom is het de moeite waard om clomifeencitraat te overwegen, vooral bij mannen met symptomen van hypogonadisme en een laag testosterongehalte die hun voortplantingsvermogen willen behouden en niet in aanmerking komen voor testosterontherapie. Lage tot normale waarden van het luteïniserend hormoon 
op baseline lijkt de biochemische en klinische effectiviteit van testosterontherapie te voorspellen. Verder onderzoek met duidelijke inclusiecriteria, adequate meting van hormoonspiegels en registratie van symptomen en bijwerkingen is aan te bevelen.

Open Access This article is distributed under the terms of the Creative Commons Attribution 4.0 International License (http://creativecommons.org/licenses/by/4.0/), which permits unrestricted use, distribution, and reproduction in any medium, provided you give appropriate credit to the original author(s) and the source, provide a link to the Creative Commons license, and indicate if changes were made.

\section{Literatuur}

1. Nieschlag E, Behre HM, Nieschlag S. Andrology-male reproductive health and dysfunction. Berlin, Heidelberg: Springer; 2010.

2. Araujo AB, O’Donnell AB, Brambilla DJ, et al. Prevalence and incidence of androgen deficiency in middle-aged and older men: estimates from the Massachusetts male aging study. JClin Endocrinol Metab. 2004;89(12):5920-6.

3. Dohle G, Arver S, Bettocchi C, Kliesch S, Punab M. Guidelines on male hypogonadism. Eur Assoc Urol. 2018;48(5):703-11.

4. Khera M, Adaikan G, Buvat J, Carrier S, et al. Diagnosis and treatment of testosterone deficiency: recommendations from the fourth international consultation for sexual medicine (ICSM 2015). J Sex Med. 2016;13(12):1787-804.

5. ZarotskyV,Huang MY, Carman W, etal. Systematicliterature review of the risk factors, comorbidities, and consequences of hypogonadism in men. Andrology. 2014;2(6):819-34.

6. Hall SA, Esche GR, Araujo AB, et al. Correlates of low testosterone and symptomatic androgen deficiency in a population-based sample. J Clin Endocrinol Metab. 2008;93(10):3870-7.

7. Wu FC, Tajar A, Beynon JM, et al. Identification of late-onset hypogonadism in middle-aged and elderly men. N Engl J Med. 2010;363(2):123-35.

8. Traish AM. Benefits and health implications of testosterone therapy in men with testosterone deficiency. Sex Med Rev. 2018;6(1):86-105.

9. Pastuszak AW, Gomez LP, Scovell JM, Khera M, Lamb DJ, Lipshultz LI. Comparison of the effects of testosterone gels, injections, and pellets on serum hormones, erythrocytosis, lipids, and prostate-specific antigen. Sex Med. 2015;3(3):165-73.

10. Saad F, Aversa A, Isidori AM, Zafalon L, Zitzmann M, Gooren L. Onset of effects of testosterone treatment and time span until maximum effects are achieved. Eur J Endocrinol. 2011;165(5):675-85.

11. Gagnon DR, Zhang TJ, Brand FN, Kannel WB. Hematocrit and the risk of cardiovascular disease - the Framingham study: a 34-year follow-up. Am Heart J. 1994;127(3):674-82.

12. Surampudi P, Swerdloff RS, Wang C. An update on male hypogonadism therapy. Expert Opin Pharmacother. 2014;15(9):1247-64.

13. Wiehle R, Cunningham GR, Pitteloud N, et al. Testosterone restoration by enclomiphene citrate in men with secondary hypogonadism: pharmacodynamics and pharmacokinetics. BJU Int. 2013;112(8):1188-200.

14. Rodriguez KM, Pastuszak AW, Lipshultz LI. Enclomiphene citrate for the treatment of secondary male hypogonadism. ExpertOpin Pharmacother. 2016;17(11):1561-7.
15. Advisory committee industry briefing document. Bone and reproductive urologic drugs advisory committee. 2016. https://fda.report/media/101593/IndustryBriefing-Information-for-the-December-6--2016Meeting-of-the-Bone-Reproductive-and-UrologicDrugs-Advisory-Committee.pdf.

16. Kaminetsky J, Hemani ML. Clomiphene citrate and enclomiphene for the treatment of hypogonadal androgen deficiency. Expert Opin Investig Drugs. 2009;18(12):1947-55.

17. Zorginstituut Nederland. Medicijnkosten.nl. 2021. https:// www.medicijnkosten.nl/. Geraadpleegd op: 12 mei 2021.

18. Huijben M, Lock MTWT, de Kemp VF, de Kort LMO, van Breda HMK. Clomiphene citrate for men with hypogonadism: a systematic review and meta-analysis. Andrology. 2022;1-19.

19. Krzastek SC, Sharma D, Abdullah N, et al. Long-term safety and efficacy of clomiphene citrate for the treatment of hypogonadism. J Urol. 2019;202(5):1029-35.

20. Soares AH, Horie NC, Chiang LAP, et al. Effects of clomiphene citrate on male obesity-associated hypogonadism: a randomized, double-blind, placebo-controlled study. Int J Obes. 2018;42(5):953-63.

21. Da Ros CT, Averbeck MA. Twenty-five milligrams of clomiphene citrate presents positive effect on treatment of male testosterone deficiency-a prospective study. Int Braz J Urol. 2012;38(4):512-8.

22. Keihani S, Wright LN, Alder NJ, et al. Baseline gonadotropin levels and testosterone response in hypogonadal men treated with clomiphene citrate. Urology. 2020;142:119-24.

23. Mazzola CR, Katz DJ, Loghmanieh N, Nelson CJ, Mulhall JP. Predicting biochemical response to clomiphene citrate in men with hypogonadism. J SexMed. 2014;11(9):2302-7.

24. PatelDP, Brant WO, Myers JB, et al. The safety and efficacy of clomiphene citrate in hypoandrogenic and subfertile men. Int J Impot Res. 2015;27(6):221-4.

25. Ribeiro RS, Abucham J. Clomiphene fails to revert hypogonadism in most male patients with conventionally treated nonfunctioning pituitary adenomas. Arq Bras Endocrinol Metabol. 2011;55(4):266-71.

26. Pasqualotto FF, Fonseca GP, Pasqualotto EB. Azoospermia after treatment with clomiphene citrate in patients with oligospermia. FertilSteril. 2008;90(5):2014.el1-2014.e12.

27. Moskovic DJ, KatzDJ, Akhavan A, ParkK, Mulhall JP.Clomiphene citrate is safe and effective for long-term management of hypogonadism. BJUInt. 2012;110(10):1524-8.

28. Taylor F, Levine L. Clomiphene citrate and testosterone gel replacement therapy for male hypogonadism: efficacy and treatment cost. J SexMed. 2010;7:269-76.

29. Marconi M, Souper R, Hartmann J, Alvarez M, Fuentes I, Guarda FJ. Clomiphene citrate treatment for late onset hypogonadism: riseandfall. IntBrazJUrol. 2016;42:1190-4.

30. Guay AT, Jacobson J, Perez JB, Hodge MB, Velasquez E. Clomiphene increases free testosterone levels in men with both secondary hypogonadism and erectile dysfunction: who does and does not benefit? Int J Impot Res. 2003;15(3):156-65.

31. Liel Y. Clomiphene citrate in the treatment of idiopathic or functional hypogonadotropic hypogonadism in men: a case series and review of the literature. Endocr Pract. 2017;23(3):279-87.

32. Raheem OA, Chen TT, Akula KP, et al. Efficacy of non-testosterone-based treatment in hypogonadal men: a review. Sex Med Rev. 2021;9(3):381-92.

33. Chandrapal JC, Nielson S, Patel DP, et al. Characterising the safety of clomiphene citrate in male patients through prostate-specific antigen, haematocrit, and testosterone levels. BJUInt. 2016;118(6):994-1000. 
34. Wheeler KM, Smith RP, Kumar RA, Setia S, Costabile RA, Kavoussi PK. A comparison of secondary polycythemia in hypogonadal men treated with clomiphene citrate versus testosterone replacement: a multi-institutional study. JUrol. 2017;197(4):1127-31.

35. An J, Cheetham TC, Van Den Eeden S. PS3-36: testosterone replacement therapy patterns for aging males in a managed care setting. Clin Med Res. 2013;11(3):141.
36. Kavoussi PK, Machen GL, Wenzel JL, et al. Medical treatments for hypogonadism do not significantly increase the risk of deep vein thrombosis over general population risk. Urology. 2019;124:127-30.

drs. Manou Huijben, anios urologie

drs. M.T.W.T. (Tycho) Lock, uroloog 